\title{
Comparison of stability of seven biochemistry analytes in serum separator and plasma tubes
}

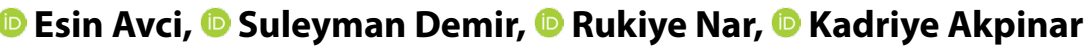

Department of Medical Biochemistry, Pamukkale University Faculty of Medicine, Denizli, Turkey

\begin{abstract}
Objectives: The aim of the present study was to compare the stability of 7 routine analytes using a BD Vacutainer Barricor plasma blood collection tube, a BD Vacutainer SST (Becton Dickinson and Company, Franklin Lakes, NJ, USA) and a Vacusera SST ((Disera A.S., Izmir, Turkey).

Methods: Five $\mathrm{mL}$ blood samples from 60 volunteers were collected into the 3 tubes. Glucose, urea, creatinine, lactate dehydrogenase (LD), sodium ( $\mathrm{Na}$ ), chloride $(\mathrm{Cl})$ and potassium $(\mathrm{K})$ levels were analyzed at $0,4,8$, and 12 hours on a Cobas 8000 analyzer ((F. Hoffmann-La Roche Ltd., Basel, Switzerland). Bias and bias\% results were calculated and compared to clinically acceptable limits (CAL).

Results: Intraclass correlation results revealed excellent agreement in the 7 chemistry analytes between the 3 tubes (0.863-1.000). The CAL for $\mathrm{Cl}$, creatinine, glucose, $\mathrm{K}, \mathrm{LD}, \mathrm{Na}$ and urea are $3 \mathrm{mmol} / \mathrm{L}, 10 \%, 0.3 \mathrm{mg} / \mathrm{dL}, 10 \%, 0.5 \mathrm{mmol} / \mathrm{L}$, $20 \%, 3 \mathrm{mmol} / \mathrm{L}$ and $2 \mathrm{mg} / \mathrm{dl}$, respectively. At the $12^{\text {th }}$ hour, there was a difference observed in glucose between Barricor-SST and Barricor-Vacusera SST were $10.06 \mathrm{mg} / \mathrm{dL}$ (11.38 \%) and $11.14 \mathrm{mg} / \mathrm{dL}(-12.76 \%)$. Analytical coefficient (CV) of variation results for glucose, $\mathrm{LD}$, creatinine, urea, $\mathrm{Na}, \mathrm{K}$, and $\mathrm{Cl}$ were $3.22 \%, 5.80 \%, 5.28 \%, 3.90 \%, 2.00 \%, 1.95 \%$, and $1.37 \%$ respectively.

Conclusion: Although the stability of all 7 analytes was within the CAL during a 12-hour period, clinically different results were obtained. In terms of stability evaluation, the use of plasma might be preferable in clinical laboratories. The routine chemistry analytes studied were within the clinically acceptable range in both plasma and serum specimens, but validation and estimation of reference intervals for plasma tubes are needed.
\end{abstract}

Keywords: Evaluation, plasma, serum, stability

T he total testing process includes preanalytical, analytical, and postanalytical phases based on the brain-to-brain loop concept [1]. The preanalytical phase is the primary source of laboratory mistakes in clinical laboratories [2]. Numerous studies have indicated that this remains a matter of interest and concern to laboratory physicians. Errors in this phase lead to an increase in hospital costs of between $0.5 \%$ and $1.5 \%$ [3].

The International Federation of Clinical Chemistry and Laboratory Medicine Working Group on Laboratory Errors and Patient Safety (IFCC WG-LEPS) created a list of quality indicators for reducing errors in the laboratory as well as 16 quality indicators related to important preanalytical steps required for the reliability of laboratory results, such as proper blood collection, the correct specimen type, and timely processing $[2,4]$.

Clinical laboratories commonly use plasma and serum separating tubes (SSTs) to analyze chemistry analytes. It has been reported that the polymer gel used in these tubes is interfering with most analytes [5]. Becton, Dickinson and Company (BD, Franklin Lakes, NJ, USA) developed the BD Barricor plasma tube, which has a mechanical barrier. According to the manufacturer, this tube requires a shorter centrifugation time and provides improved plasma quality and a longer stability period than the primary tube.

Address for correspondence: Esin Avcı MD. Pamukkale Universitesi Tip Fakultesi, Tibbi Biyokimya Anabilim Dali, Denizli, Turkey Phone: +90 5337427123 E-mail: eavci@pau.edu.tr ORCID: 0000-0002-9173-0142

Submitted Date: October 18, 2019 Accepted Date: December 19, 2019 Available Online Date: January 30, 2020

${ }^{\circ}$ Copyright 2020 by International Journal of Medical Biochemistry - Available online at www.internationalbiochemistry.com OPEN ACCESS This work is licensed under a Creative Commons Attribution-NonCommercial 4.0 International License. 
There are several studies in the literature examining stability when using Barricor plasma tubes in a biochemistry panel. The objective of this study was to analyze the stability of 7 routine analytes: urea, lactate dehydrogenase (LD), creatinine, glucose, $\mathrm{Na}, \mathrm{K}$, and $\mathrm{Cl}$, using Barricor tubes, BD Vacutainer SST II tubes (BD, Franklin Lakes, NJ, USA), and Vacusera SST tubes (Disera A.S., Izmir, Turkey).

\section{Materials and Methods}

\section{Subjects and collection tubes}

The study was conducted in the Research and Training Hospital of at Pamukkale University Hospital and included 60 apparently healthy volunteers. The study received approval from the Non-Interventional Clinical Research Ethics Committee of Pamukkale University on 27.11.2018. We collected $5 \mathrm{~mL}$ venous blood samples from each study participant into Vacutainer SST II, Barricor, and Vacusera SST tubes. Randomization, filling volume, mixing tubes, and 30-minute clotting time for serum tubes were monitored during the blood draw. Centrifuge conditions were monitored by an observer in the laboratory. All of the tubes were centrifuged at $4000 \mathrm{rpm}$ for 10 minutes under temperature control. The serum and plasma samples were visually inspected and hemolyzed samples were excluded. Fibrin particles were removed, if present. Likely sample drawing, in sample analysis we regarded randomization.

\section{Instruments}

Glucose, $\mathrm{Na}, \mathrm{Cl}, \mathrm{K}$, urea, creatinine, and LD levels were analyzed at $0,4,8$, and 12 hours on a Cobas 8000 c702 automated biochemistry analyzer (F. Hoffmann-La Roche Ltd., Basel, Switzerland). Glucose, urea, creatinine, and LD levels were analyzed using an electrochemiluminescent method, while an ion selective electrode method was used for $\mathrm{Na}, \mathrm{Cl}$, and $\mathrm{K}$ levels. All analyzer flags were noted. Internal and external quality studies were performed for 2 days and in a monthly rotation for all of the biochemistry parameters.

\section{Statistical analysis}

Descriptive statistics are presented as median and interquartile range. Intraclass correlation coefficients (ICC) were used to identify the agreement and relationship between tubes.

Bias and bias\% values were determined using the Vacusera SST tube as a reference. Bias and bias\% values were compared with the clinically acceptable limits (CAL) provided by Westgard QC (https://www.westgard.com/clia.htm). Statistical analysis was performed using IBM SPSS Statistics for Windows, Version 25.0 (IBM Corp., Armonk, NY, USA). A p value of $<0.05$ was considered statistically significant.

Analytical variation was calculated from the repeated results used in the internal quality control for each analyte. Nested analysis of variance was used to perform variate analysis.

\section{Results}

Baseline, $4^{\text {th }}, 8^{\text {th }}$, and $12^{\text {th }}$ hour measurements of the levels of the different parameters in the Vacutainer SST II, Barricor, and Vacusera SST tubes are compared in Table 1. Analyte levels were presented as median and interquartile range. The intraclass correlation coefficient (ICC) values were between 0.9-1.0 and accepted as indicating high similarity, with the exception of the Na ICC value of 0.869 at the $12^{\text {th }}$ hour (Table 1). The Clinical Laboratory Improvement Amendments proficiency testing limits to determine acceptable analytical performance for $\mathrm{Cl}$, creatinine, glucose, $\mathrm{K}, \mathrm{LD}, \mathrm{Na}$ and urea are $3.0 \mathrm{mmol} / \mathrm{L}, 0.3$ $\mathrm{mg} / \mathrm{dL}, 10.0 \%, 0.5 \mathrm{mmol} / \mathrm{L}, 20.0 \%, 3.0 \mathrm{mmol} / \mathrm{L}$, and $2 \mathrm{mg} / \mathrm{dl}$, respectively. The 7 routine chemistry analytes studied were within the acceptable limits for clinical laboratories according to Westgard QC, except glucose. The differences observed between the Barricor and the Vacutainer SST II and the Barricor and the Vacusera SST were $10.06 \mathrm{mg} / \mathrm{dL}(11.38 \%)$ and 11.14 $\mathrm{mg} / \mathrm{dL}(-12.76 \%)$, respectively (Table 2 ).

Figure 1 shows the concentration over time of the 7 parameters in the Vacutainer SST II, Barricor, and Vacusera SST tubes.

The analytical coefficient of variation results for glucose, LD, creatinine, urea, $\mathrm{Na}, \mathrm{K}$, and $\mathrm{Cl}$ were $3.22 \%, 5.8 \%, 5.28 \%, 3.9 \%$, $2 \%, 1.95 \%, 1.37 \%$ respectively.

\section{Discussion}

The present study evaluated the stability of 7 routine chemistry analytes in plasma and serum specimens at the $4^{\text {th }}, 8^{\text {th }}$, and $12^{\text {th }}$ hours after blood collection in the Barricor tube, the Vacutainer SST II, and the Vacusera SST tubes routinely used in our laboratory. Our results revealed that the chemistry analytes were all within the CAL at all time intervals, with the exception of glucose at the $12^{\text {th }}$ hour when comparing the Barricor/SST and the Barricor/Vacusera SST findings.

When we evaluated the changes in glucose, aspartate aminotransferase (AST), LD, and K concentrations, we noticed fluctuations of these analytes were different from those seen in serum.

The workload of clinical laboratories has increased in recent decades, which means that sample stability and storage are becoming even more important. There has been significant discussion in the literature about how blood collection materials and devices can alter chemistry test results.

Blood collection tubes with additives can affect test results. In the analytical phase, the most preferred sample type is serum. SSTs contain silica particles, which facilitates clotting. The gel moves upward to the supernatant-cell interface during centrifugation, which could result in interference with the results in analysis of many routine chemistry parameters. These effects could result in instability [5-7]. Cuhadar et al. [6] found no significant differences between gel or non-gel tubes, but they noted some restrictions must be applied for glucose, aspartate-aminotransferase, blood urea nitrogen, high-density lipoprotein, and uric acid storage for prolonged periods of time in gel tubes.

The Barricor tube is a single-use plastic tube with a mechanical separator that stretches into the tube bottom during centrifu- 


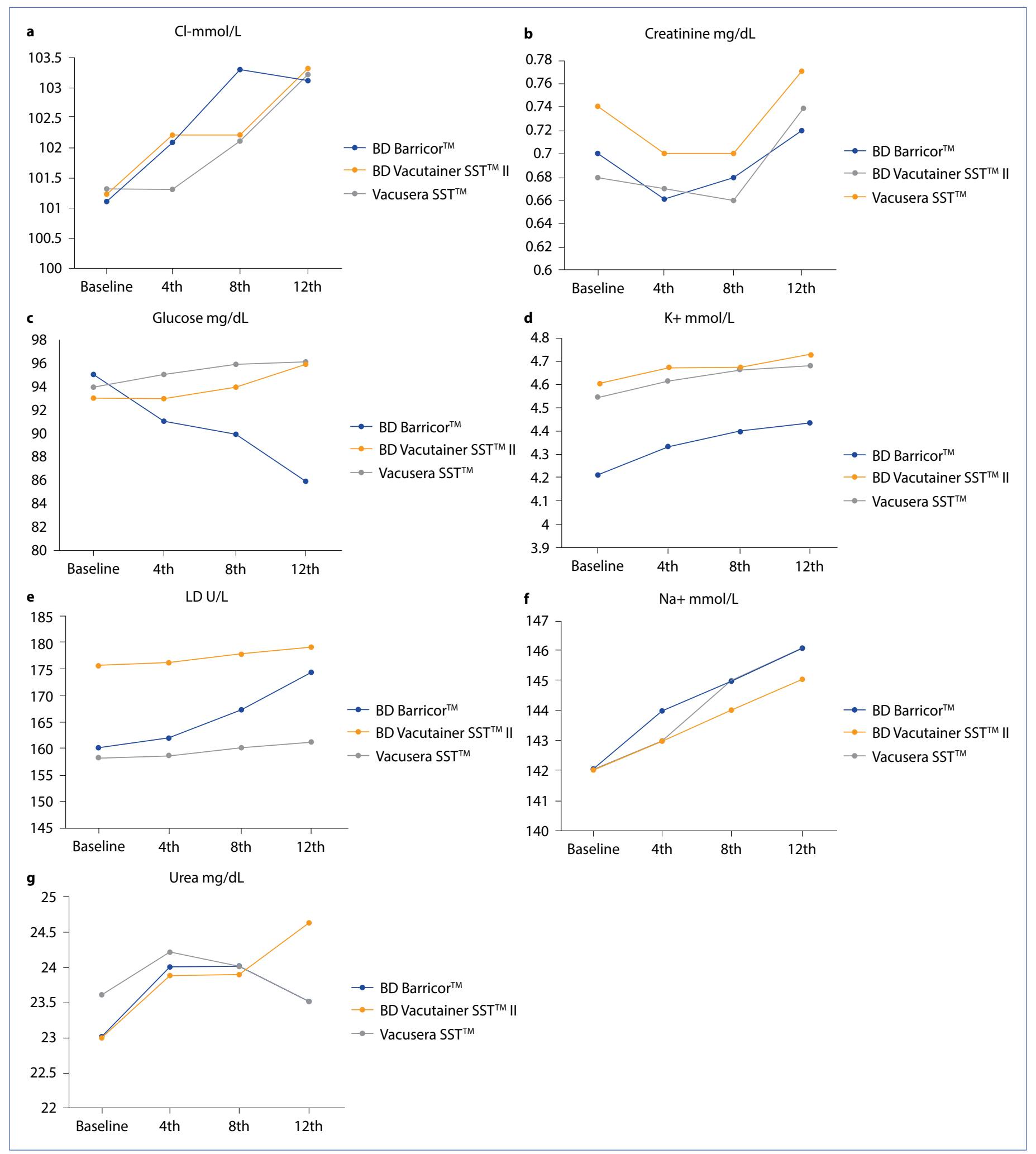

Figure 1. Concentrations over time (hours) in 3 tubes for 7 analytes: (a) chloride, (b) creatinine, (c) glucose, (d) potassium, (e) lactate dehydrogenase, (f) sodium, (g) urea. (BD Barricor and Vacutainer SST II: Becton, Dickinson and Company, Franklin Lakes, NJ, USA; Vacusera SST: Disera A.S., Izmir, Turkey).

gation. BD has claimed that this tube has enhanced plasma quality by lowering the cell count in plasma. Our study examined whether the use of plasma could improve the stability of the biochemistry analytes. Glucose concentrations decreased in the Barricor tube over time, whereas in the other 2 tubes have limited in CAL. Some plasma cells were still present and 
Table 1. Intraclass correlation for the 7 analytes in 3 tubes at each time interval

\begin{tabular}{|c|c|c|c|c|c|c|}
\hline Analyte & Unit & Time (hours) & \multicolumn{3}{|c|}{ Median (interquartile range) } & ICC (95\% CI) \\
\hline \multirow[t]{4}{*}{$\mathrm{Cl}$} & $\mathrm{mmol} / \mathrm{L}$ & Baseline & $101(99-103)$ & $101(98.5-102.5)$ & $101(98-102.5)$ & $0.992(0.987-0.995)$ \\
\hline & $4^{\text {th }}$ & $102(100.5-103)$ & $102(100-104)$ & $101(100-103)$ & $0.978(0.964-0.987)$ & \\
\hline & $8^{\text {th }}$ & $103(101-104)$ & $102(100.5-104)$ & $102(101-104)$ & $0.972(0.954-0.984)$ & \\
\hline & $12^{\text {th }}$ & $103(101.5-105)$ & $103(101-104)$ & $103(101-105)$ & $0.984(0.973-0.990)$ & \\
\hline \multirow{2}{*}{ Creatinine } & $8^{\text {th }}$ & $0.68(0.59-0.85)$ & $0.66(0.61-0.87)$ & $0.7(0.63-0.87)$ & $0.983(0.972-0.990)$ & \\
\hline & $12^{\text {th }}$ & $0.72(0.62-0.92)$ & $0.74(0.62-0.9)$ & $0.77(0.65-0.94)$ & $0.993(0.989-0.996)$ & \\
\hline \multirow[t]{3}{*}{ Glucose } & $\mathrm{mg} / \mathrm{dL}$ & Baseline & $95(84.5-104)$ & $93(85.5-105)$ & $94(86-104)$ & $1.000(1.000-1.000)$ \\
\hline & $4^{\text {th }}$ & $91(82-100.5)$ & $93(85.5-104.5)$ & $95(86.5-105)$ & $1.000(0.999-1.000)$ & \\
\hline & $8^{\text {th }}$ & $90(79-98)$ & $94(85-105)$ & $96(86.5-105.5)$ & $0.999(0.998-0.999)$ & \\
\hline K & $12^{\text {th }}$ & $4.43(4.19-4.68)$ & $4.72(4.54-4.93)$ & $4.68(4.51-4.92)$ & $0.968(0.948-0.981)$ & \\
\hline \multirow[t]{4}{*}{ LD } & $\mathrm{U} / \mathrm{L}$ & Baseline & 160 (149-201.75) & $175.5(158.25-203)$ & $158(142.25-187.75)$ & $0.995(0.992-0.997)$ \\
\hline & $4^{\text {th }}$ & $162(150.75-206.5)$ & $176(160.75-201.5)$ & $158.5(143-187)$ & $0.993(0.988-0.996)$ & \\
\hline & $8^{\text {th }}$ & $167(155.7-212.75)$ & $177.5(162-205.25)$ & $160(144-192.25)$ & $0.990(0.984-0.994)$ & \\
\hline & $12^{\text {th }}$ & $174(158.5-216.25)$ & $179(163.5-208.75)$ & $161(146.25-191.75)$ & 0.987 (0.979-0.993) & \\
\hline \multirow[t]{4}{*}{$\mathrm{Na}^{+}$} & $\mathrm{mmol} / \mathrm{L}$ & Baseline & $142(132.5-144)$ & $142(132.5-143.5)$ & $142(132.5-144)$ & $0.911(0.854-0.948)$ \\
\hline & $4^{\text {th }}$ & $144(142-145)$ & $143(141-144.5)$ & $143(141.5-144.5)$ & $0.981(0.968-0.989)$ & \\
\hline & $8^{\text {th }}$ & $145(143-146)$ & $144(142.5-146)$ & $145(143-146)$ & $0.974(0.957-0.985)$ & \\
\hline & $12^{\text {th }}$ & $146(144-148)$ & $145(143-147)$ & $146(143-147.5)$ & $0.869(0.786-0.924)$ & \\
\hline Urea & $\mathrm{mg} / \mathrm{dL}$ & Baseline & $23(18.6-28.6)$ & $23(19.2-29)$ & $23.6(19.4-29.35)$ & $0.930(0.886-0.959)$ \\
\hline
\end{tabular}

Cl: Confidence interval; ICC: Intraclass correlation; LD: Lactate dehydrogenase; BD Barricor and Vacutainer SST II: Becton, Dickinson and Company, Franklin Lakes, NJ, USA; Vacusera SST: Disera A.S., Izmir, Turkey.

glucose had metabolized into glucose-6-phosphate. Although in serum tubes, the glucose levels were within the CAL, an increase was observed. It might have been an effect of the silica separator gel effect, we concluded.

Dimeski compared the stability of potassium, glucose, LD, and phosphate in a BD plasma separator tube, a Barricor tube, a rapid serum tube, and an SST and revealed decreasing changes in potassium, LD, and phosphate concentrations due to cellular lysis and glucose. They suggested that the Barricor tube should become the new standard for lithium heparin plasma [8]. LD activity in the Barricor tube was similar to the 2 SSTs, but the rate of increase was much greater in the Barricor tube when compared with the others. Similarly, potassium increased in all of the tubes, but in the Barricor tube, the increase was $>0.2 \mathrm{mmol} / \mathrm{L}$ in 12 hours, though it was within the CAL. These findings suggested chemistry analytes in plasma have required new reference intervals.

In 2017, Arslan et al. [9] conducted a validation study analyzing 6 chemistry parameters in 22 volunteers in the Barricor tube. They performed secondary tests, including analysis of centrifugation at the $3^{\text {rd }}$ and $10^{\text {th }}$ minute and hemolysis experiments, and found clinically different results for AST and LD in plasma compared with serum. The authors concluded that the difference was not the result of hemolysis and might have been related to the number of platelets, cellular fragility, or the functional environment.

There are some limitations to our study. We compared plasma samples to serum samples, and the inclusion of another plasma tube could have added to the evaluation of plasma effects. In addition, a glass tube ( $Z$ tube) as a standard could have been used to compare all of the analytes to a reference.

Sample quality and type can influence the accuracy of the results of any test. In recent years, using plasma in routine chemistry analyses instead of serum has become an important issue. As a result of gel effects in SSTs, using plasma has become more common. Validation studies and our study suggest each tube needs its own reference intervals. 
Table 2. Comparison of bias and bias\% of 7 chemistry analytes with CAL limits

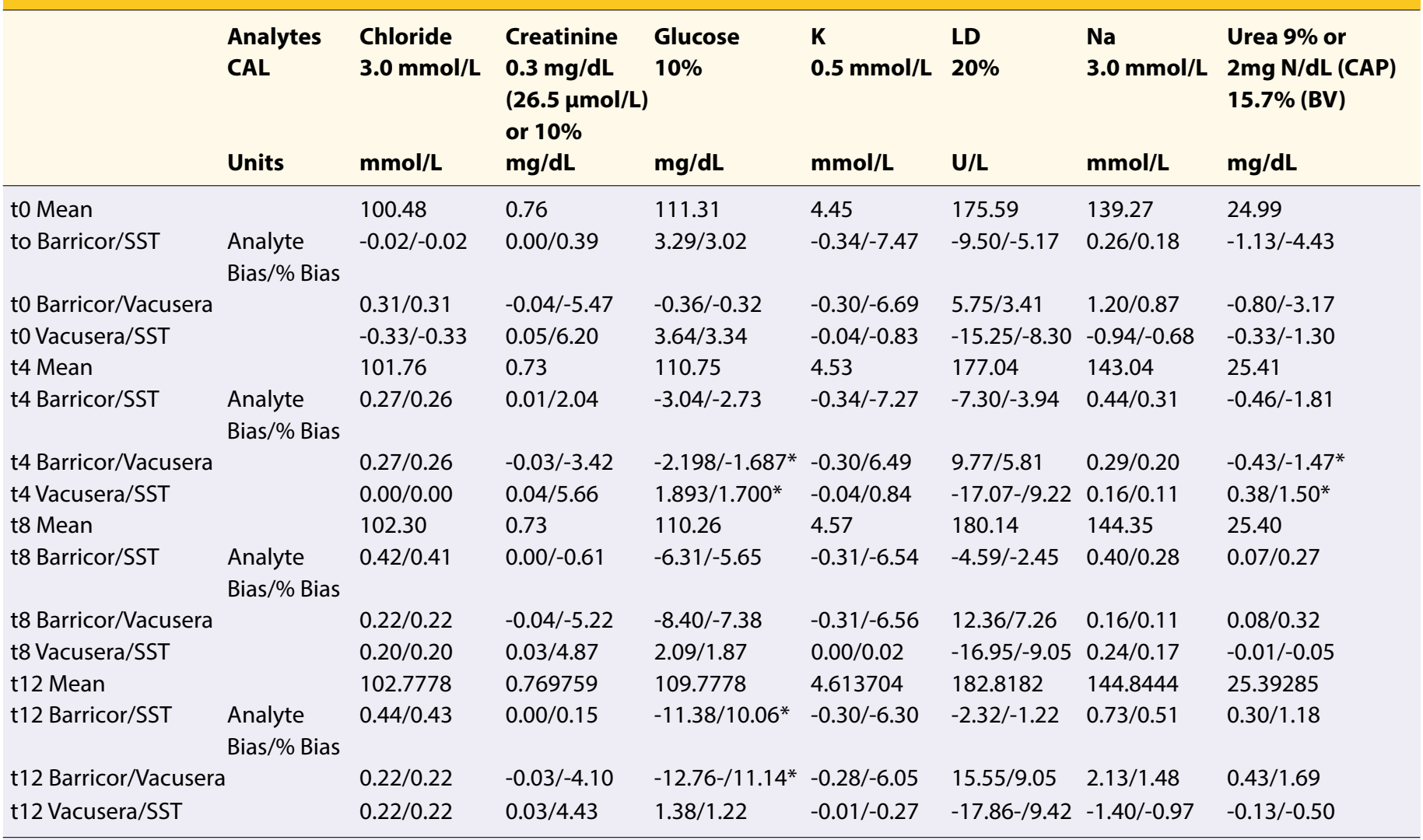

The CAL used were obtained from https://www.westgard.com/clia.htm; CAL: Clinically acceptable limits; LD: Lactate dehydrogenase; (BD Barricor and Vacutainer SST II: Becton, Dickinson and Company, Franklin Lakes, NJ, USA; Vacusera SST: Disera A.S., Izmir, Turkey).

Our stability study of 7 routine chemistry parameters revealed that plasma use continues to be an important issue in clinical laboratory practice.

We concluded that plasma meets the requirements of clinical laboratory practice and may be preferred.

Ethics Committee Approval: The study received approval from the Non-Interventional Clinical Research Ethics Committee of Pamukkale University on 27.11.2018.

Financial Disclosure: The current study was funded by BD Diagnostics (Becton, Dickinson and Company, NJ, USA) provided to the project.

Peer-review: Externally peer-reviewed.

Authorship contributions: Concept - E.A., S.D., R.N.; Design E.A., S.D., R.N.; Supervision - E.A.; Data collection \&/or processing - E.A., R.N., K.A.; Analysis and/or interpretation - E.A., K.A.; Literature search - E.A., R.N.; Writing - E.A.; Critical review - E.A., S.D., R.N., K.A.

\section{References}

1. Çuhadar S. Preanalytical variables and factors that interfere with the biochemical parameters: a review. OA Biotechnology 2013;2:19.

2. Sciacovelli L, O'Kane M, Skaik YA, Caciagli P, Pellegrini C, Da Rin $\mathrm{G}$, et al, Quality Indicators in Laboratory Medicine: from theory to practice Preliminary data from the IFCC Working Group Project "Laboratory Errors and Patient Safety". Clin Chem Lab Med 2011;49:835-44.

3. Green SF. The cost of poor blood specimen quality and errors in preanalytical processes. Clin Biochem 2013;46:1175-9.

4. Plebani M, Sciacovelli L, Aita A, Chiozza ML. Harmonization of pre-analytical quality indicators. Biochem Med (Zagreb) 2014;24:105-13.

5. Sandberg S, Christensen NG, Horgen E, Jacobsen H, Johansen K. Evaluation of Serum Separator Tubes as a Mail Transport Device in Primary Health Care. Scand J Prim Health Care 1988;6:251-4.

6. Cuhadar S, Atay A, Koseoglu M, Dirican A, Hur A. Stability studies of common biochemical analytes in serum separator tubes with or without gel barrier subjected to various storage conditions. Biochem Med (Zagreb) 2012;22:202-14.

7. Bowen RA, Remaley AT. Interferences from blood collection tube components on clinical chemistry Assays. Biochem Med (Zagreb) 2014;24:31-44.

8. Goce D, Johnston J. Is the BD Barricor Tube the New Standard for Lithium Heparin Plasma?. Developments Clin Med Pathol 2018;1:1-5.

9. Arslan FD, Karakoyun I, Basok BI, Aksit MZ, Baysoy A, Ozturk $Y K$, et al. The local clinical validation of a new lithium heparin tube with a barrier: BD Vacutainer ${ }^{\circledR}$ Barricor LH Plasma tube. Biochem Med (Zagreb) 2017;27:030706. 